\title{
artículos
}

\section{Iconografía cristiana! en la publicidad de las revistas ilustradas (1915-1935)}

\author{
Eva María Ramos Frendo \\ Universidad de Málaga
}

RESUMEN

El presente trabajo tiene como objetivo el análisis de las iconografías sagradas o sutilmente relacionadas con mundo religioso que son utilizadas por los dibujantes en los anuncios publicitarios insertos en revistas ilustradas y diarios de las primeras décadas del siglo $X X$.

PALABRAS CLAVE: Iconografía Sagrada/ Publicidad/ Revistas/ Ilustración. 1935)

Christian iconography in the advertising of the illustrated magazines (1915-

ABSTRACT

The present work intends to analiyse the sacred iconographies or related with the religions world used by the designers in the publicity of the ilustrated magazines and daily newspapers during the first decades of twenty century.

Englightenment.

KEY WORDS: Sacred Iconography/ Advertising/ Magazines/

En las primeras décadas del siglo XX -especialmente a partir de la segundase produjo un creciente protagonismo de la imagen en los anuncios publicitarios que aparecen entre las páginas de las revistas ilustradas. Hasta aquel momento el texto con tipografías y orlas variadas había sido la tónica general, teniendo la imagen un lugar muy secundario o inexistente. Se trataban de anuncios de pequeño tamaño que convivían con otros muchos en una misma página de la prensa ilustrada.

A partir del periodo a estudiar, siguiendo el modelo del cartel, el texto pasó a un segundo plano y la ilustración, en anuncios ya a toda página, ganó todo el protagonismo. Tras estas creaciones encontramos un elevado número de dibujantes entre los que se hallan los más destacados del momento: Federico Ribas, Rafael Penagos, Juan Basilio, Salvador Bartolozzi, Baldrich, Pérez Durias, Aristo Téllez, Vázquez Calleja, Juan José Labarta, Suárez Couto, Enrique Valera de Seijas, Máximo Ramos, José Zamora, Eduard Jener, Quesada Hoyo, M. C. Espi, Izquierdo y Vivas, Ricardo García (K-Hito), José Loygorri, Emilio Ferrer, Dubón, V. Ibáñez, Bagaria, Rosado

* RAMOS FRENDO, Eva María: "Iconografía cristiana en la publicidad de las revistas ilustradas (1915-1935)", en Boletín de Arte, $\mathrm{n}^{\circ}$ 30-31, Departamento de Historia del Arte, Universidad de Málaga, 2009-2010, págs. 457-478. Fecha de recepción: Mayo de 2009.

1 Agradezco las orientaciones bibliográficas facilitadas por la profesora Reyes Escalera. 
Rivas, A. Ehrmann, etc ${ }^{2}$.

En estos anuncios publicitarios emergerán una gran diversidad de iconografías y escenas ${ }^{3}$. La gran mayoría plasman la época contemporánea a los mismos, donde se puede apreciar una dualidad entre imágenes que nos hablan de la familia tradicional española, donde la mujer cumple su rol de perfecta madre y esposa, frente a otras que ilustran una España más moderna y cosmopolita -en algunos casos casi inexistente- poblada de hombres y mujeres elegantes y distinguidos. Éstas últimas se muestran sumamente a tono con las modas Europeas y Americanas, al presentar el corte a lo garçon, el sombrero cloche, las faldas más cortas y de talle bajo, y aparecen realizando actividades hasta entonces impensables entre el elemento femenino.

Junto a estas temáticas, que podríamos considerar reflejo o espejo de la sociedad del momento y de sus espacios de vida cotidiana y ocio, existen otras en las que primará la mirada hacia el pasado, recreando diversas épocas, donde destacan las que nos remiten al siglo XVIII, especialmente cuando se trata de empresas de perfumería que ven en las mujeres de esa centuria el mejor exponente del deleite en el cuidado y arreglo del aspecto.

Dentro de esa recuperación de iconografías pretéritas y demostrando un gusto generalizado por el retorno de lo clásico, existirán otras imágenes que nos permiten observar un elevado número de personajes del mundo mitológico así como obras de arte gestadas en los periodos de la antigüedad 4 . Sin embargo la iconografía cristiana, más basada en pasajes de la Biblia, las pasiones de Cristo o en los martirios y vida de santos y santas, entre otros temas, no será tan apropiada para el reclamo publicitario, por lo que son menos abundantes, aunque no inexistentes. Curiosamente, al contrario de lo que ha sido habitual en las artes plásticas, especialmente en la pintura, son mucho más abundantes los personajes y escenas extraídos del Antiguo Testamento frente a los del Nuevo.

Dentro de los del Nuevo Testamento casi el único tema, pero con abundante aparición, serán los tres Reyes Magos y siempre en coincidencia con la fecha de celebración de su Epifanía. Es también destacada la abundante presencia de ángeles que actuarán como protectores del género humano y también las escenas macabras, con la figura de la muerte, que suelen ser habituales en anuncios de carácter curativo.

Igualmente, la escasez de imágenes religiosas es una tónica general en el resto

2 Sobre los ilustradores gráficos de estas décadas cfr. PÉREZ ROJAS, F. J: Art Déco en España, Madrid, Cátedra, 1990, págs. 67-167; "Antología de ilustradores de "Blanco y Negro"” en Blanco y Negro. 1891-1966. Número de 196 págs. conmemorativo de nuestro 75 aniversario, 7 de mayo de 1966. Existen además monográficos sobre figuras como Rafael Penagos, Salvador Bartolozzi y Federico Ribas: Penagos 1889-1954, Madrid, Fundación Cultural Mapfre Vida, 1989. VELA CERVERA, D.: Salvador Bartolozzi (1882-1950): ilustración gráfica, escenografía, narrativa y teatro para niños, Zaragoza, Tesis doctoral inédita, 1996. AA. VV.: Federico Ribas. Exposición Antológica, Vigo, Caixavigo, 1991.

3 Un acercamiento a esa variedad de íconos aparece reflejado en nuestro trabajo "Iconografía publicitaria de una década en Blanco y Negro 1915-1925)", Cuadernos de Arte e Iconografía n 34, Madrid, 2009, en prensa.

4 La presencia de lo clásico en la publicidad ha sido abordado en nuestro trabajo "Iconos del mundo clásico en la publicidad de las revistas ilustradas españolas (1915-1935)", Revista Imafronte, Universidad de Murcia, en prensa. 
de páginas de las revista ilustradas, frente al mayor componente de las profanas. Estas iconografías se hacen más abundantes coincidiendo con las fechas navideñas o durante Semana Santa, siendo casi inexistentes en el resto de las publicaciones anuales.

Cuando fuera de estas fechas se alude a alguna creación de temática religiosa de autores contemporáneos -como es el caso de las obras que Mateo Inurria ${ }^{5}$ nos plasma en 1921- el resultado son creaciones muy clásicas, siguiendo el estilo academicista, que se alejan del sentimentalismo y la expresividad de la veta barroquizante española. No obstante, existirán algunos artistas -José Gutiérrez Sonala, Zuloaga o Regoyos- que plasman en sus obras una religiosidad popular envuelta en un carácter pesimista y muy influenciado por el estilo de los artistas del Siglo de Oro español pero que, como el mismo Dalí expondría ${ }^{6}$, serán la excepción en una época caracterizada por la decadencia de la pintura religiosa .

Por esa razón, el estudio de las imágenes sagradas que son utilizadas por la publicidad de comienzos del siglo $X X$ es el objetivo del presente trabajo, a fin de observar como lo tradicional se adapta a unos nuevos fines y significados al ser utilizado por los medios de masas de la edad contemporánea7. Debemos tener en cuenta que se tratan de unas temáticas que desde la segunda mitad del siglo XIX habían caído en desuso, como consecuencia de encontrarse en una época en la que la que sociedad era totalmente descreída, había perdido el sentir religioso colectivo y la iglesia carecía de poder para dirigir las conciencias ${ }^{8}$.

Ante todo no podemos olvidar que el anuncio comercial tiene una principal función, la persuasión de las personas que observan dichas imágenes para llevarlas a una determinada acción, la compra del producto mostrado. Es fundamental para el creador publicitario generar una necesidad en el cliente que será cubierta gracias a la adquisición del objeto que se le está ofertando. En muchas ocasiones, éste fue el fin de la pintura religiosa, convencer por medio de la incitación emocional para llevar al fiel a una determinada actuación que, en estos casos, estaría destinada a la recapacitación sobre los comportamientos pecaminosos y la adopción de unos nuevos modelos de conducta especialmente ante la amenaza del paso del tiempo fugaz y la

\footnotetext{
5 “El sentimiento cristiano en Mateo Inurria", La Esfera, 2 de julio de 1921.

6 BLÁZQUEZ, J. M.: "La pintura religiosa de Gutiérrez Solana y la iconografía de la muerte en la pintura contemporánea", Anales de Historia del Arte n 9, Servicio de Publicaciones de Universidad Complutense 1999, Madrid, pág. 306.

7 Esta actualización o reinterpretación de lo sagrado por parte del vídeo-clip ha sido abordada por el profesor Sánchez López en varios de sus trabajos. Cfr. SANCHEZ LÓPEZ, J.A., "Medios de masas e Iconografía: la imagen religiosa al servicio del vídeo-clip", Boletín de Arte, n 13-14, Universidad de Málaga, 1992-1993, págs. 369-389 y SANCHEZ LÓPEZ, J. A.: "Basquiat y EI Bosco recuperados. El mito de la culpa y la caída en imágenes del vídeo-clip: 'Until it sleeps' Metállica, 1996”, Boletín de Arte n² 23, Universidad de Málaga, 2002, págs. 565-600. También podemos hallar algunos ejemplos en FUENTES CARRASCO, M.: "Entre el monstruo y el mártir: los vídeos musicales de Marilyn Manson (1995-2001)”, Boletín de Arte n 26-27, Universidad de Málaga, 2005-2006, págs. 759-782. Igualmente se ha analizado este fenómeno en la fotografía publicitaria actual: Cfr. TORRES AGUILAR, F.: "Retórica de la publicidad, publicidad neobarroca", Boletín de Arte $\mathrm{n}^{\circ}$ 26-27, Universidad de Málaga, págs. 711-744.

8 ÁLVAREZ LOPERA, J.: "La crisis de la pintura religiosa en la España del siglo XIX", Cuadernos de Arte e Iconografía, tomo 1, I, Madrid, Fundación Universitaria Española, 1988, pág. 81.
} 
posible llegada de la muerte ${ }^{9}$. Por tanto, aunque con un objetivo muy diferente, en ambos casos estas iconografías cumplen un mismo fin, el enganche con el espectador para conducirles a una determinada acción, aunque con todas las obvias diferencias entre unas y otras imágenes.

\section{ESCENAS E IMÁgenES EXTRAIDAS DEL ANTIGUO TESTAMENTO.}

Si nos guiamos por el orden de aparición dentro de la Biblia, las escenas primeras a las que nos podemos referir, procedentes del Antiguo Testamento, serán las que nos reflejan pasajes del Génesis ${ }^{10}$ relacionados con el Jardín del Edén y las figuras de Adán y Eva11 que son mostradas solas o en compañía de Dios. En las imágenes halladas los ilustradores se han movido con todo tipo de libertades y anacronismos y han tenido el humor como uno de los principales ingredientes o recursos dentro del anuncio publicitario. Por el contrario, en estos mismos años, el tema de Adán y Eva era igualmente tratado con un lenguaje mucho más esquematizado y vanguardista por Jorge Lescanulzer, miembro del Grupo Noviembre, ubicados dentro del expresionismo alemán ${ }^{12}$.

Una de estas imágenes nos presenta a Dios con forma antropomórfica, siguiendo la costumbre que se hizo habitual desde la Edad Media ${ }^{13}$, y presentando un aspecto similar al descrito por el profeta Daniel: “...un anciano...Su vestido era blanco como nieve, su cabellera como la lana limpísima"14. Su cabeza aparece coronada con el triángulo equilátero, monograma de Cristo o referencia a la Trinidad y porta en sus manos unas tablas que pueden tratarse de las "losas de piedra con la ley y los mandatos..."15 que Dios entregó a Moisés. Dios se dispone ante unos atípicos Adán y Eva en medio de un paraje boscoso y deshabitado. Posiblemente por decoro - dado que se tratan de figuras relacionadas con el mundo de lo sagrado-16

9 RODRÍGUEZ ORTEGA, N.: "La imagen persuasiva Barroca. Algunas reflexiones al hilo de una hipótesis de lectura: El Camarín-Torre de la Victoria y la Cripta de San Lázaro de Málaga, un imagen textual", Boletín de Arte $\mathrm{n}^{\circ} 17$, Málaga, Universidad de Málaga, 1996, págs. 229-258.

10 Biblia del Peregrino Génesis, 2, Bilbao Ediciones $\lambda$, 1995, pág. 1214.

11 RÉAU, L.: Iconografía del arte cristiano. Iconografía de la Biblia. Antiguo Testamento, tomo 1, vol. 1, Barcelona, Serbal, 1996, págs. 101-110. Para conocer unas nuevas lecturas sobre el pecado de Adán y Eva cfr. GONZÁLEZ DE LA LLANA FERNÁNDEZ, N.: Adán y Eva, Fausto y Dorian Gray: tres mitos de trasgresión, Madrid, Universidad Complutense de Madrid, 2006.

12 "El arte y la extravagancia. Esculturas expresionistas" en La Esfera, 7 de agosto de 1920. Se representa la obra El nacimiento de Eva.

13 REAU, L., Iconografía del... op. cit., pág. 28.

14 Biblia del Peregrino... op. cit., Daniel 7, 9.

15 Ibídem, Éxodo 24, 12.

16 En el caso de imágenes profanas la sensualidad y exhibición de las anatomías femeninas fue bastante habitual en estas décadas al mostrarlas en su cuidado e higiene diaria apenas tapadas con ligeras y resbaladizas prendas. Cfr. RAMOS FRENDO, E. M.: “Imágenes seductoras en la publicidad de las revistas ilustradas", en Actas del Congreso Internacional Imagen y Apariencia, Murcia, 2008, en http://congresos.um.es/imagenyapariencia/11-08/schedConf/presentations. 
se descarta la representación habitual de ambos desnudos. Adán presenta unos calzones, mientras Eva lleva una corta faldita y sus senos son cubiertos por unas trenzas rematadas por unos lazos que tienen la suficiente dimensión para dejar poco pecho al descubierto. Para completar lo cómico de la imagen Adán presenta bigote, puro y monóculo, mientras Eva remata su cabeza con una peineta.

Por tanto, no consideramos que la presencia de prendas que cubran su desnudes se puedan, tanto en éste como en los siguientes ejemplos que vamos a exponer, relacionar con el hecho de que sean escenas posteriores al pecado y donde ambos se sienten avergonzados de su estado natural, sino que se debe a motivos más bien de recato y que, por tanto, se despegan de la forma de representación habitual en toda la historia del arte y según lo expuesto en los textos que nos los representarían siempre desnudos y sin sentir pudor hasta que la consumación del pecado los haga huir de dicho estado.

El tema de Adán y Eva ha permitido, a lo largo de la historia del arte, a los artistas, la representación de desnudos en las artes plásticas, mientras, en el caso de los ilustradores gráficos, no fue aprovechado para tal fin.

Y por si todo esto fuera poco, en el anuncio que estamos analizando, el supuesto Paraíso es recorrido por una avioneta que lleva impreso el nombre del producto publicitado "Tarayina" un milagroso curativo. Dios se dirige a la pareja y con el brazo alzado de manera imperativa se dirige a ellos pronunciando las palabras que nos ilustra el texto: "Y Dios les dijo: - Creced, multiplicaos...y si padecéis de estómago, tomad la Tarayina Tridigestiva del Boticario de Elda"17. Se trata de un anuncio de pequeño formato que comparte página con otros más.

A toda página se nos presenta un nuevo Jardín del Edén salido de las manos del dibujante Rafael Penagos con un estilo humorístico que lo aleja del estilo elegante y estilizado en que se mueve habitualmente con sus jóvenes modernas y sus ambientes cosmopolitas ${ }^{18}$ [1].

En esta ocasión diversas especies del mundo animal acompañan a la pareja (chimpancé, jirafa, elefantes, seres acuáticos, aves, etc.). En primer plano a la izquierda se sitúa el Árbol del bien y del mal cuyos frutos son innumerables pastillas del Jabón Flores del Campo, el objeto del anuncio. La serpiente se enrosca en su tronco y asciende sobre una de las ramas para ofrecer de manera tentadora una de las citadas pastillas a Eva. Adán, con un aspecto musculoso y primitivo, con largas barbas y melenas de color oscuro, vuelve el rostro hacia el espectador evitando la mirada de su compañera, mientras el cuerpo se dispone hacia dentro de la composición creando un escorzo que contribuye a evitar la visión de la desnudez frontal de su cuerpo.

Eva, de frente hacia nosotros y con una cabellera que le tapa la totalidad de la anatomía, alza la mano hacia el objeto ofertado (sustituto del fruto prohibido). El texto parece ilustrar las palabras de la serpiente la cual exhorta a Eva diciéndole: "-¡Eva!..., ¡¡vvita!!... Evita... usar otro jabón.” Y ella responde, no sabemos con seguridad si diri-

17 ABC, 6 de octubre de 1922.

18 Mundo Gráfico, 19 de mayo de 1915. Ilustración de Rafael Penagos. 

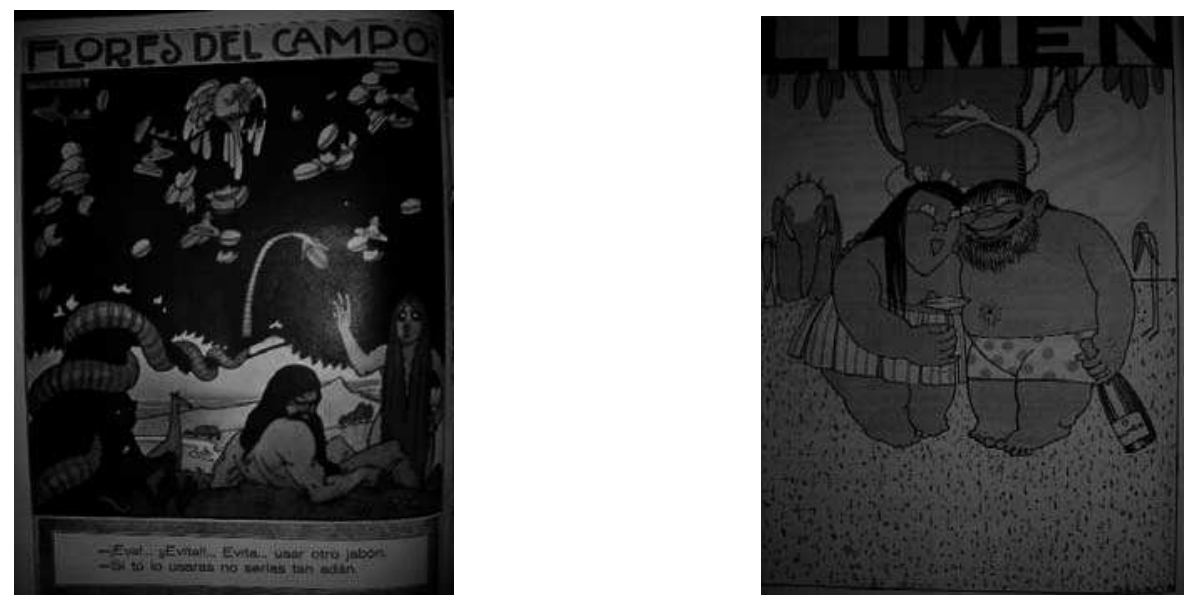

1. Ilustración de Rafael Penagos: "Mundo Gráfico", 19-5-1915.

2. Ilustración de Bagaria: "España", 14-11-1919.

giéndose a su pareja o a la serpiente tentadora: "Si tú lo usaras no serias tan adán." Con esta afirmación y teniendo en cuenta que el anuncio publicita un producto para la higiene corporal, Eva se está refiriendo a la definición que la palabra adán presenta en el Diccionario de la Lengua Española: "Hombre desaliñado, sucio o haraposo"19.

Con nuevo carácter humorístico y presentando anatomías que nos recuerdan a los voluminosos cuerpos surgidos de la mano de Rubens o incluso más cercanos a las de Botero, Bagaria [2] nos presenta una enamorada pareja -algo que queda remarcado no solo por el acercamiento físico de ambos sino, a su vez, por la forma acorazonada de la boca de Eva- que se dispone centralizando la escena en un primer plano, mientras el árbol del bien y el mal y la serpiente enrollada en su tronco se disponen en un segundo plano que divide simétricamente la composición que quedaría ligeramente desestabilizada por el desigual número de animales que flanquean dicho elemento natural y que serán la referencia a los animales y criaturas voladoras que puse en el jardín del Edén. Esta disposición simétrica sigue la que fue la composición habitual en las representaciones de este tema en el románico 20 . De nuevo las dos figuras humanas utilizan prendas que cubran la desnudes.

La copa del árbol queda rematada por el nombre en mayúsculas y con una destacada tipografía del producto publicitado, el champán LUMEN, que en esta ocasión contribuirá, según se aprecia por el texto, a incentivar el pecado. Lo que resulta

19 Diccionario de la Lengua Española. Madrid, Real Academia Española, 2001, pág. 42.

20 SAÉNZ RODRÍGUEZ, M.: "La iconografía de Adán y Eva en la escultura monumental del arte románico en La Rioja", Berceo, nº 126, Logroño, 1994, pág. 22. 
3. Ilustración de Pérez Durias: "ABC", 4-5-1922.

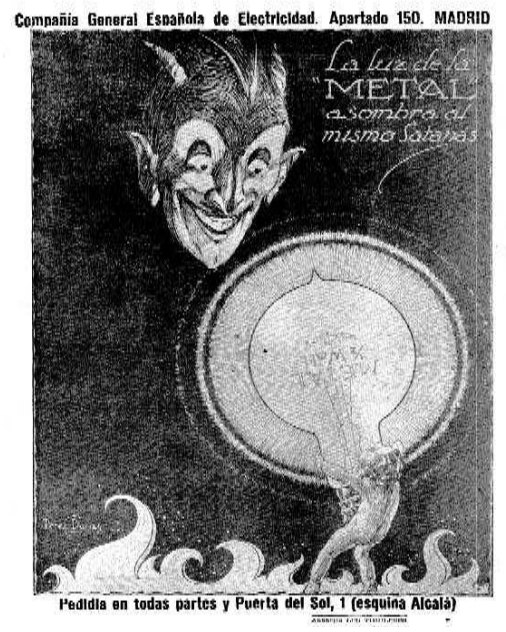

novedoso en esta escena es que, contradiciendo lo plasmado por los textos y lo reflejado por las artes plásticas a lo largo de toda la historia del arte, se concede un mayor protagonismo e iniciativa en la acción que conducirá al pecado a la figura masculina. Adán, con una mirada algo lasciva, invita a Eva a consumar el pecado pero haciéndolo, gracias a la ingestión del champán Lumen, mucho más original. Mientras ella sostiene la copa vacía en su mano derecha, él igualmente porta la botella aún sin descorchar con la que ofertará la bebida prohibida21. Por tanto se rompe con ese papel inocente de Adán y con esa condenación a Eva por considerarla la principal responsable del pecado 22 . Se trata de una visión que se opone a lo que había sido habitual durante el fin de siglo que recurrió a la figura de Eva junto a otras figuras históricas femeninas (Salomé, Judith, etc.) para incidir en él.

Este mismo tema, bajo el título La última manzana, fue también, por estas fechas, realizado por el mismo artista en la caricatura presentada al Salón de Humoristas de Avilés que se inauguró el 17 de agosto de 1925 en la Escuela de Artes y Oficios ${ }^{23}$. De nuevo unos atípicos Adán y Eva que se acercan en su representación más al mundo animal que al humano, especialmente la figura masculina con un aspecto desproporcionado y totalmente primitivo, que nos recuerda más a los antepasados del hombre que a su evolución final.

Relacionado con el episodio de Adán y Eva está el Diablo que adoptará la forma de la serpiente incitadora al pecado, tal y como hemos observado en las dos imágenes previas. Pero las referencias a esta fuerza del mal se siguen dando a lo largo de todo

21 España, 14 de noviembre d3 1919, Ilustración de Bagaria.

22 SAÉNZ RODRÍGUEZ, M.: "La iconografía de Adán y Eva... op. cit., pág. 21.

23 FRANCÉS, J.: "El Salón de Humoristas de Aviles" en La Esfera, 26 de septiembre de 1925. 


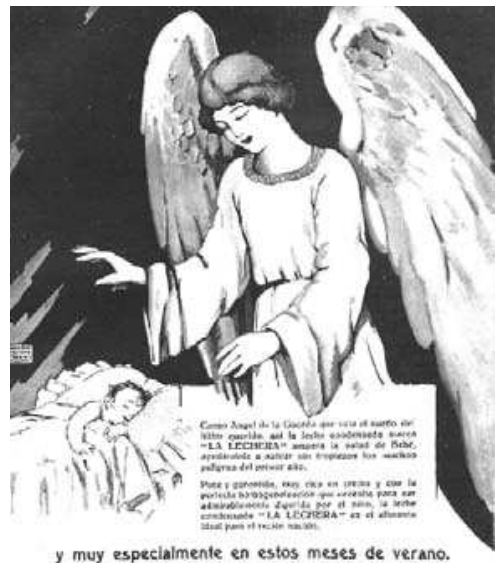

y muy especialmente en estos meses de verano.

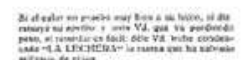

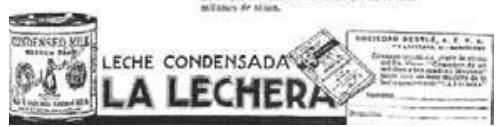

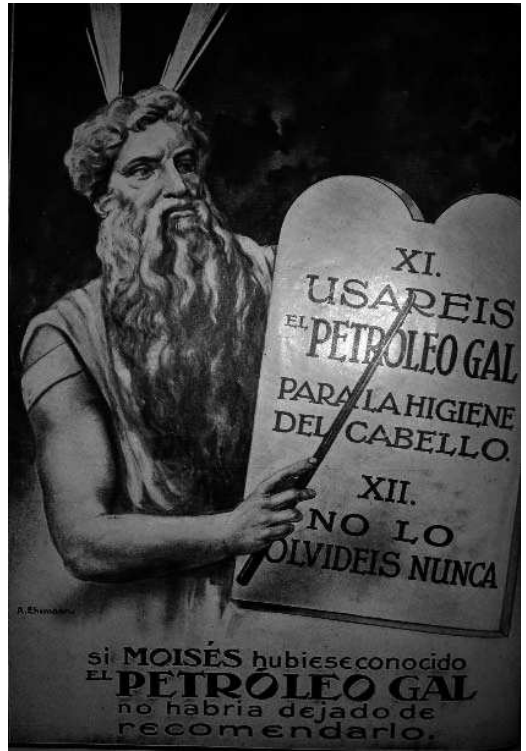

4. "Nuevo Mundo", 8-7-1927.

5. Ilustración de A. Ehrmann: "Mundo Gráfico", 30-7-1912.

el Antiguo Testamento, en los Evangelios y en el Apocalipsis y en las artes plásticas adquirirá diversas apariencias ${ }^{24}$. También la publicidad utiliza en diversas ocasiones esta iconografía e incluso en la actualidad toda la publicidad y su discurso persuasivo se consideran como un nuevo ser demoníaco y tentador que crea paraísos artificiales 25 .

De la mano de Pérez Durias [3] tenemos un busto del personaje que emerge de la oscuridad y cuya representación se asimila a la de los sátiros y faunos al mostrar las orejas picudas y los cuernos. Es, por tanto, un claro reflejo de los préstamos de la mitología griega ${ }^{26}$. Presenta una sonrisa que, más que temor, nos transmite la sensación de lascivia tan habitual en los acompañantes de Baco pero que, según nos indica el texto, sería reflejo del asombro que le produce la visión del objeto publicitado. El producto es la bombilla Metal de gran potencia que está portando una diminuta figura infantil -dispuesta en la parte inferior en diagonal con la cabeza del Diablo

\footnotetext{
24 Sobre los diversos aspectos que puede presentar el Diablo cfr. YARZA LUACES, J.: "Del ángel caído al diablo medieval", Boletín del Seminario de Estudios de Arte y Arqueología: BSAA, tomo 45, Universidad de Valladolid, 1979, págs. 299-316.

25 Sobre la consideración del discurso publicitario como demoníaco cfr. FERNÁNDEZ SEVILLA, J. D.: "La publicidad o de los nombres del diablo", Comunicar. Revista Científica Iberoamericana de Comunicación y Educación, n² 20, Grupo Comunicar, 2003, págs. 178-183.

26 REAU, L., Iconografía del...op. cit., págs. 80 y 83-85.
} 
ubicada arriba- la cual parece haber descendido al mundo infernal -lo que se deduce por las llamas que se disponen a los pies del amorcillo- para enfrentarse al mismo diablo. El fin es transmitirnos la gran luminosidad del producto anunciado que logra vencer a la oscuridad, representada por Satán 27.

De nuevo, en un anuncio de pequeñas dimensiones que comparte página con otros más, encontramos un busto largo del Diablo28. En esta ocasión presenta, además de los atributos antes citados, las alas de murciélago que desde la Edad Media se hacen habituales y porta un tridente. Pero quizás por la creencia de que el mal vence al mal se convierte en una personificación positiva al identificarse con el insecticida Nao-Jip que acaba con todo tipo de plagas: escarabajos, hormigas, cucarachas, ratas, chinches, piojos, etc. Por tanto su uso en la publicidad, al menos en los ejemplos hallados hasta el momento, aparecen totalmente desligados de acontecimientos concretos de los reflejados en la Biblia, si exceptuamos los casos en que personificado como serpiente acompaña a las figuras de Adán y Eva.

En otra ocasión hemos hallado a la figura del Diablo bajo el nombre de Mefistófeles pero, en este caso, inserto en una escena que hace referencia a la obra de Fausto y por tanto, se insertará dentro de un futuro trabajo en que se abordaran los temas literarios en la publicidad que nada tiene que ver con la iconografía sagrada que aquí estamos tratando.

Igualmente los ángeles también aparecerán en diversos anuncios. Se tratan de seres creados por Dios para propiciar una relación entre éste y los hombres. Los ángeles no tienen un lugar concreto en la Biblia dado que son mencionados en diversas ocasiones tanto en el Antiguo como en el Nuevo Testamento. En la literatura medieval se abordaban tres dimensiones funcionales en los ángeles: mensajeros, auxiliadores y portadores de almas 29 .

Las dos primeras son las que hemos podido ver abordadas por la publicidad. En el primer caso incluiríamos a aquellos ángeles que transmiten el mensaje de la empresa -considerada como el ente supremo que busca el bien de sus clientes- para beneficio de los consumidores. Éste sería el caso del reconstituyente Ruamba cuyo fabricante, el doctor Viñas, se encarga de su recomendación a las madres por medio del texto escrito, argumentando que él lo ha probado en sus propios hijos. La imagen nos presenta una niña placidamente dormida en su lecho sobre la que flotan, dispuestos sobre sendas nubes, dos angelotes que portan el objeto recomendado 30 .

La empresa Gal también utilizará a querubines que portan los objetos que repercutirán positivamente en las clientas que los usen. Mientras se recomiendan los polvos Flores de Talavera en el texto, por todos los bienes que proporcionarán al cutis femenino, un angelote, suspendido junto al embase del producto, lo aplica con una borla sobre

$27 A B C, 4$ de mayo de 1922. Ilustración de Pérez Durias.

28 ABC, 5 de mayo de 1923.

29 MARÍN UREÑA, J. M.: “Estelas de los ángeles celestiales en la literatura medieval española”, Lemir. Revista de Literatura Española Medieval y del Renacimiento n 8, Universidad de Valencia, 2004, pág. 4.

30 ABC, 19 de marzo de 1921. 
una destinataria invisible ${ }^{31}$. Otro querubín, creado por Ribas, se convierte en el responsable de verter sobre el pañuelo que sostiene el brazo de una supuesta mujer el perfume del Agua de Colonia Añeja ${ }^{32}$. Un angelote, ilustrado por Juan Basilio, será también objeto de los anuncios de la empresa Luca de Tena al ser el portador de un cofre cargado de esperanzas y promesas felices, lo que el cliente conseguirá en el nuevo año que entra si consume el sedativo para los nervios Agua de Azahar La Giralda33.

En la función de ángel que media para salvar a los mortales estaría el custodio o de la guarda ${ }^{34}$, el más venerado por la Compañía de Jesús tras los ataques protestantes. Un claro ejemplo de esta figura celestial encontramos en el anuncio de "La Lechera" [4]. Se plasma, como era habitual en su interpretación pictórica y escultórica, por medio de la figura de un niño junto al que está el ser angélico Pero si lo habitual es que el niño aparezca interrogando al ángel con su mirada, aquí este primero se encuentra totalmente dormido mientras el ser angelical vela su vigilia disponiendo las manos a ambos lados de la camita mientras lo contempla.

La figura celestial presenta los rasgos e indumentarias usuales en estos seres: aspecto joven, melena larga y aparentemente rubia -aunque sin apreciarse con claridad si posee o no diadema-, expresión risueña, túnica vaporosa y ajustada que se ciñe en la cintura, unas potentes alas y unas facciones bastante femeninas ${ }^{35}$. Si la imagen muestra claramente la función protectora de la figura angelical, el texto viene a reafirmar el mensaje al indicarnos que "Como Ángel de la Guarda que vela el sueño del hijo querido, así la leche condensada marca "LA LECHERA" ampara la salud del Bebé ayudándole a salvar sin tropiezos los muchos peligros del primer año"36. Por tanto, el producto publicitado viene a sustituir el papel que anteriormente había tenido otorgado esta figura de la esfera divina. Anuncios como éste vienen a mostrar como claramente la publicidad se va apropiando de iconografías y funciones anteriormente ofrecidas por el mundo religioso. La felicidad que en un pasado garantizaba dicha religión ahora la prometen las distintas empresas a través de sus productos.

Siguiendo el orden de aparición dentro del Antiguo Testamento, del libro del Éxodo, el segundo personaje bíblico que hallamos es la figura de Moisés ${ }^{37}$-una de las figuras consideradas como premonitorias de Jesús-38 en una imagen realizada

31 Blanco y Negro, 30 de marzo de 1924.

32 Blanco y Negro, 17 de marzo de 1929.

$33 A B C, 2$ de enero de 1924.

34 Sobre su origen e iconografía cfr. URREA, J.: “Ángeles napolitanos", Boletín del Seminario de Estudios de Arte y Arqueología: BSAA, tomo 50, Universidad de Valladolid, 1984, págs. 442-445. También se puede profundizar en esta figura en MARÍN UREÑA, J. M.: "Estelas de los ángeles... op. cit., págs. 5-7.

35 Idéntico aspecto es el que se nos describe en GONZÁLEZ ISIDORO, J.: "Aproximación a un estudio iconológico de los ángeles, santos y alegorías en la ciudad de Carmona", Carel: Carmona: Revista de Estudios Locales $\mathrm{n}^{\circ} 3$, Ayuntamiento de Carmona, enero de 2005, pág. 1106.

36 Nuevo Mundo, 8 de julio de 1927.

37 Mundo Gráfico, 30 de julio de 1912. Ilustración de A. Ehrmann

38 CALVO CASTELLÓN, A.: "Iconografía del Antiguo Testamento en la obra de los grandes maestros de la pintura barroca andaluza", Cuadernos de Arte e Iconografía, tomo I, 1, Madrid, Fundación Universitaria Española, 1988, págs. 135-158. 
por A. Ehrmann [5], principal ilustrador de la casa Gal en sus primeros años. Se trata de la única imagen del este libro que hemos hallado en publicidad algo que, si no se modifica con futuros hallazgos, coincide numéricamente con la producción del mismo tema que existió dentro de la pintura barroca española al haberse localizado un solo cuadro surgido de la mano de Murillo39.

La iconografía de Moisés que nos muestra este anuncio presenta una gran similitud con la imagen creada por Miguel Ángel para la Iglesia de San Pietro in Vincoli salvo por algunas diferencias. Al igual que la obra citada, el Moisés de Ehrmann -plasmado en un busto largo que nos permite ver hasta la cintura- presenta las largas barbas blancas y un atuendo similar al de la escultura creada por Miguel Ángel pero, en esta imagen publicitaria, han desaparecido los cuernos que por error de traducción de la Vulgata comenzaron a llevar algunas imágenes a partir del siglo $\mathrm{XII} 40$ y, por el contrario, presenta, coronando el busto, unos haces de luz que pueden aludir a ese resplandecimiento que sufrió su rostro al descender tras recibir las Tablas de la Ley de Dios ${ }^{41}$. Las citadas tablas también aparecen en la escena pero, en lugar de bajo el brazo como las porta la figura de Miguel Ángel, se disponen ante el espectador para servir de soporte a las recomendaciones que el libertador del pueblo judío nos va a dar. Las Tablas de la Ley sustituyen el mandato divino por exhortaciones acerca del uso del Petroleo Gal, producto objeto de este anuncio. La recomendación XI será: "Usareis el Petroleo Gal para la higiene del cabello"42 y la XII incide en que no lo olviden nunca.

Sansón 43 , cuyas hazañas se relatan en el Libro de los Jueces (13-16), aparece en una sola ocasión en la publicidad [6]. Se nos presenta en la parte inferior del anuncio en una escala menor que el busto de mujer que se dispone en la zona superior. Su cuerpo, de musculatura muy marcada, nos refleja esa fortaleza que le destacó, mientras apenas advertimos la larga cabellera en la que, tal y como nos expone el anuncio, residía "El secreto de la fuerza de Sansón..."44. Por lógica, dada la importancia del cabello en la figura del héroe bíblico, es escogido para publicitar el Agua Cruspinera, cuyo recipiente porta en uno de sus brazos. Se trata, según se nos expone, del producto clave al que se debe "...el secreto de la belleza de la mujer moderna..." para tener unos hermosos cabellos. Por tanto, la joven que observamos y Sansón guardan cada uno un secreto -fuerza y hermosura res-

39 Ibídem.

40 DUCHET-SUCHAUX, G. y PASTOREAU, M.: Guía Iconográfica de la Biblia los santos, Madrid, Alianza Editorial, 1996, págs. 277-279. Otras interpretaciones sobre el tema de los cuernos de Moisés se pueden ver en RUIZ DE ELVIRA, A.: "Los "hermanos" de Jesús y la iconografía de Moisés", Epos: Revista de Filología $\mathrm{n}^{\circ} 10$, Universidad Nacional de Educación a Distancia, 1994, págs. 60-67.

41 REAU, L., Iconografía del... op. cit., págs. 212-214 y 242-243.

42 Mundo Gráfico, 30 de julio de 1912. Ilustración de A. Ehrmann.

43 RÉAU, L.: Iconografía del... op. cit., págs. 279-293.

44 Blanco y Negro, 4 de diciembre de 1927. 

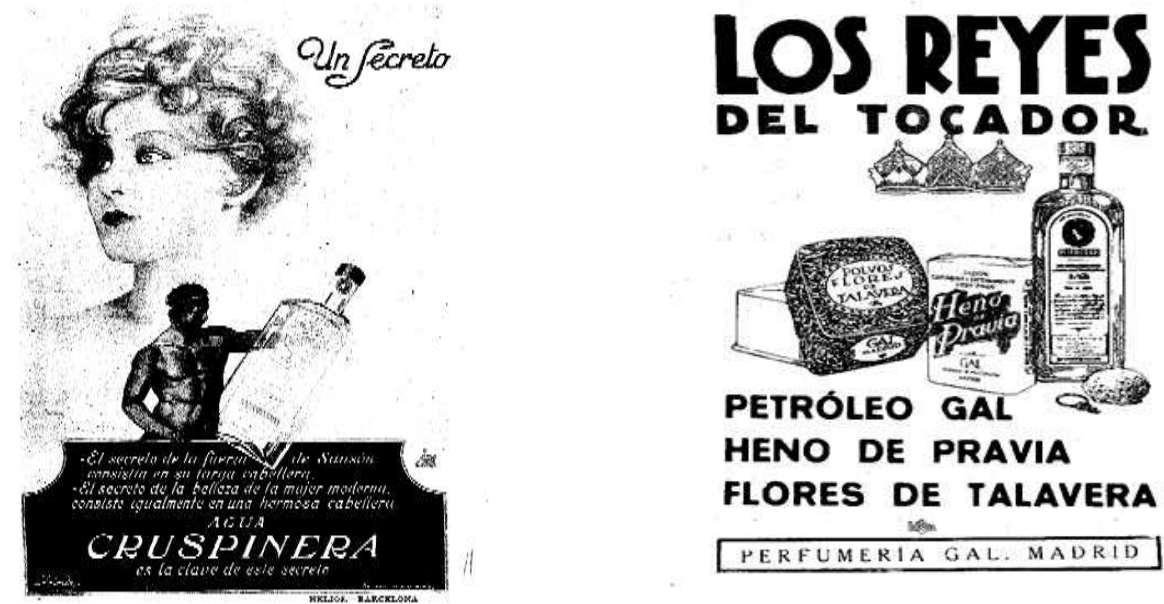

DEL TOGADOR

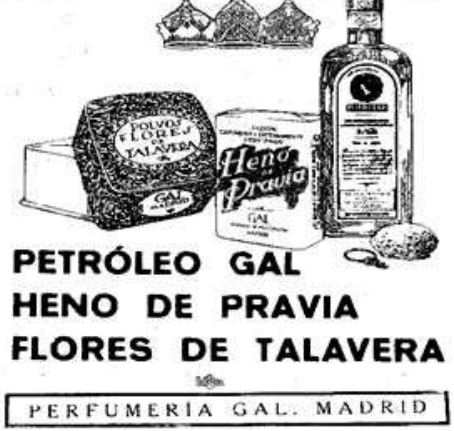

6. "Blanco y Negro", 4-12-1927.

7. Ilustración de Federico Ribas: “ABC”, 6-1-1920.

pectivamente- relacionado con sus cabellos por lo que se les representa unidos en este mismo espacio.

\section{Escenas e imágenes del Nuevo Testamento.}

Las figuras que observamos de manera más habitual dentro de la iconografía sagrada utilizada por la publicidad, siempre coincidiendo con las fechas navideñas, son los Magos de Oriente 45 , el total de tres y como reyes según las diferentes aportaciones literarias han ido perfilando a partir de lo que se especificara inicialmente en el Evangelio de San Mateo y como finalmente la misma Iglesia estableció por consenso a través de las declaraciones del papa León I el Grande ${ }^{46}$.

Se da una recuperación totalmente profana de los mismos que nada tiene que ver con la Epifanía o Adoración del Niño Dios por parte de los Magos. Solo en uno de los anuncios hallados se plasma la escena de "La adoración de los magos" 47 , de por sí la que más habitualmente nos refleja a dichos Magos en las artes plásticas, en el

45 Sobre la iconografía de los Reyes Magos Cfr. BANGO, I.: "Sobre el origen de la prosquinesis en la Epifanía de los Magos", Traza y Baza, n 7, Universidad de Barcelona, 1978, págs. 25-37; GARCÍA MAHÍQUES, R.: La Adoración de los Magos. Imagen de la Epifanía en el Arte de la Antigüedad, Vitoria-Gasteiz, Ephialte, 1988. GONZÁLEZ REQUENA, J.: Los Tres Reyes Magos. La edificación simbólica, Madrid, Akal, 2002; GRAUDIECKMANN, P.: "Una iconografía polémica: los Magos de Oriente": Mirabilia Revista Electrónica de Historia Antigua y Medieval, 2, Editores Ricardo da Costa, 2002; RÉAU, L.: Iconografía del arte cristiano. El Nuevo Testamento, Tomo I, vol. 2, Barcelona, Ed. Del Serbal, 1996-98, págs. 247-266.

46 GRAU-DIECKMANN, P.: "Una iconografía polémica... op. cit.

47 ABC, 22 de diciembre de 1920. 
resto se nos presentan de las formas más diversas como distribuidores de regalos procedentes de almacenes y bazares o de alguna empresa concreta.

El Gran Bazar de la Unión los presenta montados en una especie de globo o "zeppelin" desde el cual van lanzando los juguetes esperados por los niños 48 . Melchor y Gaspar se muestran activos a ambos lados del artefacto volador mientras Baltasar, en el centro, muestra una total quietud, puede que motivado por el temor a desestabilizar el aparato y romper el equilibrio. Al fondo se divisa la silueta de la ciudad. Los tres personajes recogen el aspecto habitual de Melchor de pelo oscuro, Gaspar de barba blanca, con sus respectivas coronas y, finalmente, Baltasar de raza negra tocado con turbante.

Heno de Pravia también hará uso de estos personajes que, como emisarios de la empresa Gal, sustituyen las ofrendas que llevaron al Niño Dios por el producto estrella de esta perfumería, el jabón Heno de Pravia, que, para mayor realce, disponen sobre un lujoso cojín rojo. En esta ocasión los tres llevan atuendos orientalizantes con turbantes, piedras preciosas, plumas y presentan un porte muy solemne mirando directamente hacia el espectador. Baltasar queda de nuevo en el centro resaltando el fuerte colorido de las capas de los otros dos magos. Los tres magos se disponen arrodillados sobre un suelo plagado de rosas rojas. Esta imagen fue realizada por Federico Ribas, a todo color, para servir de portada a la revista Mundo Gráfico49.

Para esta misma empresa, seguramente también Ribas, se realiza otro nuevo anuncio que, en esta ocasión, sustituye las figuras de los magos, por tres de sus productos que son considerados "Los Reyes del Tocador": Jabón Heno de Pravia, Petroleo Gal y Flores de Talavera [7]. Sobre los tres embases se disponen otras tantas coronas que refuercen dicha condición de realeza. Si puede quedar alguna duda a la alusión que se quiere llevar a cabo con los Magos de la iconografía cristiana aún quedará más claro si se tiene en cuenta que esta imagen fue publicada en el diario $A B C$ el día 6 de enero50.

Igualmente la empresa Renault también hace un montaje similar al que vimos de Heno de Pravia y en este caso, entre los tres -en una imagen totalmente clásica por su composición y de nuevo solemnes, enmarcados por la estrella de oriente que se dispone al fondo incidiendo aún más en la simetría de la imagen- portan un modelo de los ofrecidos por la casa fabricante [8]. Mientras Baltasar se ubica al centro marcando una cierta diferencia, los otros dos reyes lo flanquean mostrando unas imágenes casi clónicas, salvo por la mayor blancura de las barbas de la figura de la derecha. Las tres figuras, como si faraones egipcios o Kouros arcaicos fueran, se presentan totalmente hieráticas y en estado de quietud. Quizás la solemnidad con que se presenta todo el conjunto tiene como objetivo remarcar la superioridad del objeto que están portando y ofertando a los futuros clientes pues, como el mismo

48 ABC, 3 de enero de 1912.

49 Mundo Gráfico, 3 de enero de 1917.

50 ABC, 6 de enero de 1920. 

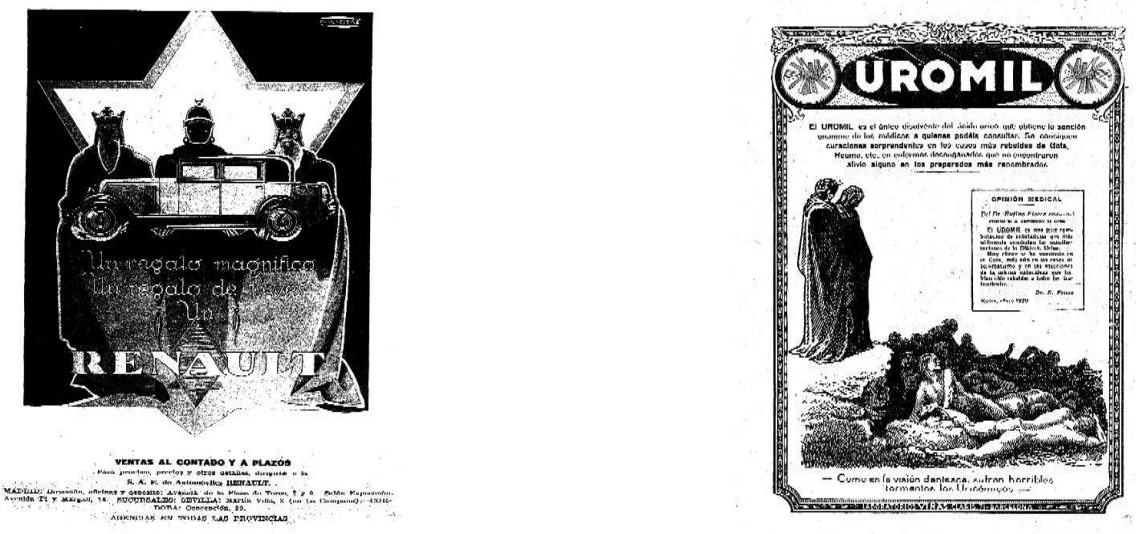

8. "Blanco y Negro", 6-1-1928.

9. " $A B C$ ", 17-12-1921.

anuncio especifica, se trata de "Un regalo magnífico. Un regalo de Reyes" 51 .

No obstante, la competencia de Papa Noel ya se va notando, pues en otros casos los bazares optan por la figura del barbudo anciano en trineo tirado por renos como dispensador de los esperados presentes navideños ${ }^{52}$. También la empresa de los familiares de don Torcuato Luca de Tena, en un diseño de su dibujante habitual, Juan Basilio, utiliza la imagen de Papa Noel en esta ocasión para hacer referencia a la llegada del nuevo año que queda personificado en un pequeño infante que el anciano porta en su saco. El anuncio hace referencia a uno de sus productos curativos, el Agua de Azahar "La Giralda" que sirve para sedar los nervios y que de esta manera contribuirá a que los clientes que lo adquieran logren con el "Año Nuevo" una "Vida Nueva" 53 Y quizás esta influencia de Papa Noel será la que lleve a otros anunciantes a presentar a un solo rey mago distribuyendo los productos anunciados en lugar de los tres habituales ${ }^{54}$.

En otros anuncios se realiza una alusión al episodio de la estrella de oriente que guía a los hombres en su camino sustituyendo la misma por el producto publicitado, las bombillas "Metal", que se dispone resplandeciente al fondo del horizonte mientras una figura a camello la contempla. En el texto, para remarcar el mensaje que la imagen ha querido lanzar, se nos indica "Luz de Oriente" 55.

\footnotetext{
51 Blanco y Negro, 6 de enero de 1928. De nuevo como vemos se vuelve a utilizar a estos tres personajes justo el día de Reyes.

52 ABC, 3 de enero de 1914.

53 Blanco y Negro, 4 de enero de 1925. llustración de Juan Basilio.

54 ABC, 4 de enero de 1923.

$55 A B C, 25$ de agosto de 1921.
} 
Este mismo recurso será utilizado nuevamente para la publicidad de un producto similar -otra bombilla denominada Zargón- pero combinando este episodio de la religión cristiana con unos personajes del ámbito literario, Don Quijote y Sancho Panza. El anuncio, creado por la agencia Los Tiroleses, nos dispone en primer término al hidalgo y su escudero que asciende una colina y al fondo de la misma se observa el reluciente objeto mientras el texto nos sirve de claro enlace con el episodio bíblico al exponernos “...y apareció en el horizonte una estrella que a los mortales indicaba el camino de la perpetua claridad" 56 . El interrogante que se nos puede presentar es a qué se debe el uso de estos personajes insertándolos en un episodio ajeno a ellos. Puede que la respuesta pueda ser la constante búsqueda de originalidad para, de este modo, enganchar con los espectadores que, en el caso del $A B C$, diariamente observarían estos anuncios.

La Virgen María, figura destacada por haber sido madre de Jesús, tan sólo aparece en dos ocasiones en la iconografía publicitaria. Una de ellas sería la, ya citada anteriormente, escena de la Epifanía de los Magos mientras, en otra ocasión, aparece bajo la advocación de la Inmaculada Concepción ${ }^{57}$, iconografía que se iniciará a finales de la Edad Media y que tendrá especial difusión en el mundo barroco español a partir del concilio de Trento cuando se intentó elevar esta doctrina a dogma de fe.

La imagen plasmada en el anuncio carece de originalidad puesto que se reduce a una copia de la iconografía murillesca para impulsar, dos días antes de la celebración de la fiesta nacional por la patrona, a los espectadores a la compra de un reloj de pulsera de la madrileña Fábrica de Relojes de Carlos Copell con el fin de agasajar a todas las Conchas. El artículo y el texto que incita a la adquisición con la frase "el regalo más práctico y útil para las Conchas..."58 se disponen bajo esa imagen enmarcada por orla floral ovalada en la que vemos a la joven flotando sobre nubes y la luna creciente con puntas hacia abajo - al contrario de lo establecido por Pacheco en su obra el Arte de la Pintura- junto con dos putti que forman parte del cortejo que contribuye a la glorificación y engrandecimiento de la figura de la Virgen 59 . La joven presenta la cabeza con aureola resplandeciente, sus ropajes, como es habitual según las recomendaciones de Pacheco, consisten en túnica blanca y manto que debe ser de color azul -algo que al tratarse de una imagen en blanco y negro no podemos apreciar- y las manos unidas en el centro del pecho mientras la cabeza se inclina hacia la izquierda a la vez que eleva la mirada y el manto se despliega hacia el lado opuesto, contribuyendo ambos elementos a romper con la simetría de la imagen y a introducir una cierta sensación de movimiento en la escena. Siguiendo dicho modelo murillesco no aparecen ninguno de los atributos salvo la luna creciente ya citada y un par de ramas sostenidas por los putti

56 ABC, 21 de noviembre de 1920.

57 Sobre la Inmaculada Concepción cfr. STRATTON, S.: "La Inmaculada Concepción en el arte español", Cuadernos de Arte e Iconografía n 2, tomo 1, Madrid, Fundación Universitaria Española, 1988, págs. 3-128. MARTINNEZ JUSTICIA, M. J.: "María, la nueva Eva. Iconografía de la mujer singular: la Inmaculada Concepción" en SAURET GUERRERO, T. (Coord.): Historia del Arte y Mujeres, Universidad de Málaga, 1996, págs. 175-202. 58 ABC, 6 de diciembre de 1921.

59 MARÍN UREÑA, J. M.: “Estelas de los ángeles... op. cit., pág. 2. 
que difícilmente podemos apreciar de que especies se tratan.

Tanto el Nuevo Testamento como los textos apócrifos hacen referencia al infierno. En el caso de la publicidad, en lugar de realizar una imagen propia, lo que hace es referencia a las visiones dantescas plasmadas en la Divina Comedia. De nuevo -como ya vimos en la Inmaculada Concepción- las ilustraciones hacen uso de imágenes que creara Gustave Doré en el siglo XIX para ilustrar dicho poema, plasmándonos al poeta acompañado de Virgilio y presenciando el sufrimiento de los condenados [9]. Esta imagen viene a reflejar que el drama por parte de los condenados es similar al que padecen aquellos que no toman el objeto publicitado, Uromil, y que por tanto son víctimas de los padecimientos que causa el Ácido Úrico60.

\section{OTRAS ICONOGRAFIAS SAGRADAS.}

Los productos curativos también hicieron uso de una iconografía muy habitual en el arte del barroco español, el esqueleto como representación de la muerte, es decir unas imágenes que entrarían dentro de lo que se denomina macabro61. Este icono ya existía en algunas culturas desde el siglo XIII, pero sobre todo se hará más habitual a partir del siglo XV62. En la Edad Moderna estas macabras imágenes recordaban a los fieles la transitoriedad de la vida y les llevaba a un arrepentimiento de los pecados ante el riesgo de un temprano o inesperado fallecimiento.

En la publicidad, por su parte, el esqueleto, siempre acompañado de la guadaña -del mismo modo que lo hacía la figura de Crono- y a veces cubierto por una capa que nos impide ver su aspecto, advierte al espectador del anuncio acerca de la necesidad de adquirir los remedios expuestos para evitar la venida de enfermedades que den el triunfo a la muerte 63 . Se trata de una iconografía que ha continuado utilizándose hasta la actualidad en otros muchos ámbitos de la cultura visual, en ocasiones como denuncia a grandes masacres debidas a las guerras o por una elevada mortandad debida a epidemias 64 .

Por tanto, como nos expone Fracesca Español, el temor a la muerte es universal y no conoce límites cronológicos ${ }^{65}$, de manera que dicha temática se va a dar en todas las épocas históricas y en las más diversas manifestaciones buscando con los cadáveres, esqueletos y calaveras crear un desasosiego y una reacción en el

60 ABC, 17 de diciembre de 1921.

61 ESPAÑOL BERTRÁN, F.: Arte Español. Lo macabro en el gótico hispano nº 70, Madrid, Historia 16, 1991, pág. 6.

62 DUARTE GARCÍA, I.: "Representaciones de la muerte en la Edad Media y el Renacimiento", Ars Medica, vol. 8, 8, Santiago de Chile, 2003.

${ }^{63} A B C, 9$ de septiembre de 1921. Soluto Vital reconstituyente que permitirá a los niños, según el anuncio, “...burlarse de la muerte". 9 de agosto de 1922: La Tarayina. 28 de febrero de 1923: nuevo anuncio de Soluto Vital.

64 ARMAS, I. de, La estructura viviente II. Anatomía artística, Madrid, You \& US, S.A., 2006.

65 ESPAÑOL BERTRÁN, F.: Arte Español. Lo macabro... op. cit., pág. 6. 

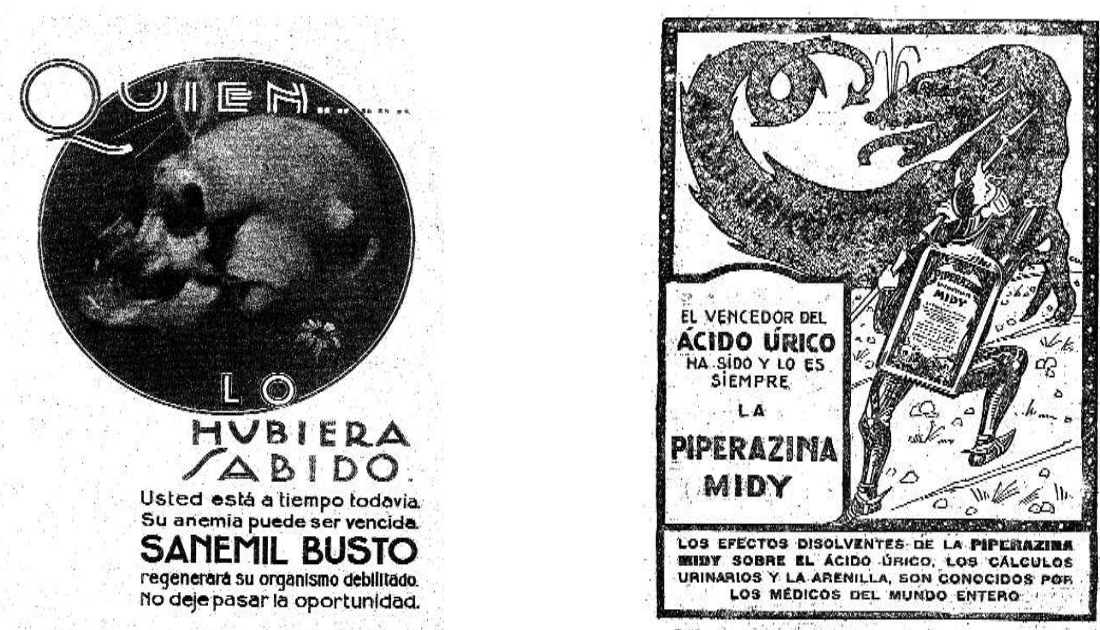

10. Ilustración de Aristo Téllez: “ABC", 15-7-1923.

11. “ $A B C$ ", 1-4-1923.

espectador. Dentro de los artistas coetáneos a los ejemplos publicitarios que estamos reflejando se encontraría la figura de José Gutiérrez Solana que hace uso del tema de la muerte y los esqueletos en diversas de sus obras 66 .

En uno de los ejemplos publicitarios hallados contamos con la presencia de la calavera [10] -lo cual fue también muy habitual en autores de época diversas como Durero, Vang Gogh, Picasso, Luis Fernández o Andy Warhol que los plasmaron solos o en otras ocasiones como elemento de compañía de santos, santas, Magdalenas, etc.- en una obra de Aristo Téllez, que nos plasma un final dramático que los espectadores del anuncio podrán evitar. Este cráneo va acompañado de la frase "Quién lo hubiera sabido..." para indicar que el representado podría haber evitado la muerte si hubiera usado Sanemil Busto que lo hubiera librado de la anemia67.

También San Jorge, figura legendaria cuyo culto se difundió desde Oriente a Occidente a raíz de las cruzadas, convirtiéndose en el patrón de los caballeros, será utilizado por la publicidad escenificando su episodio más conocido, la lucha contra el dragón que aterrorizaba a una ciudad y al que debían entregar tributos habitualmente. El santo aparece en una composición que enfrenta a fuerzas antagónicas. Mientras San Jorge personifica al producto milagroso publicitado, la Piperazina Midy, como advertimos por el torso del santo que se ha convertido en una botella del reconstituyente de la que surgen los brazos, el dragón presenta sobre su cuerpo las

66 BLÁZQUEZ, J. M.: “La pintura religiosa de Gutiérrez Solana... op. cit., págs. 295-313.

67 ABC, 15 de julio de 1923. 
palabras que define al elemento dañino a combatir, el ácido úrico68 [11].

La escena nos presenta el momento en que el santo dotado de oscura armadura y lanza, clava esta última en el cuello del fiero animal. A diferencia de la mayor parte de representaciones pictóricas ${ }^{69}$ que lo muestran a lomos de un caballo blan$\mathrm{co}$, el anuncio nos dispone al guerrero a pie. Santo y monstruo son los únicos presentes en la escena sin existir rastro de la figura de la princesa que iba a ser entregada a la bestia y que suele aparecer mayoritariamente en un segundo plano.

Una composición similar a la aquí citada también se realizó por parte de otro reconstituyente, Uromil, que igualmente atacaba los efectos dañinos del ácido úrico. Pero en dicha ocasión sustituyó al santo por los protagonistas de la famosa obra helenística, Laocoonte, y las serpientes, que intentaban acabar con la vida del sacerdote troyano y sus hijos, pasaron a ser las portadoras del texto que las identificaba con el mal a vencer. Por tanto, podríamos considerar que la lucha y tensión entre dos fuerzas antagónicas viene a ser uno de los componentes que caracterizan a la publicidad de los reconstituyentes que intentan combatir determinados males que aquejan a nuestra salud. Mientras una de las figuras (santo o héroe) viene a personificar el producto milagroso anunciado, el ser monstruoso al que se enfrenta encarna esos males y enfermedades que podrán aquejar a nuestro organismo si no hacemos caso de la recomendación del anuncio visualizado.

Dentro de este grupo tendríamos aquellas escenas que nos plasman la devoción popular acontecida en las celebraciones de Semana Santa y reflejadas en la publicidad por medio de imágenes que nos recrean los pasos procesionales y especialmente las figuras femeninas de las mantillas que participan de estos actos o de los oficios que se celebran durante dichos días. En la publicidad de las décadas estudiadas solo un anuncio nos presenta el momento del paso procesional. Se trata de un anuncio de las cámaras fotográficas Kodak, ilustrado por Fernando Marco, y las protagonistas de la imagen, dos mujeres de mantilla, en lugar de presentar una actitud devocional hacia la imagen del Crucificado que se acerca hacia ella, precedida por las filas de nazarenos penitentes, optan por recrearse en la captación del evento con su cámara de fotos de la marca publicitada ante la mirada de la joven del traje de rayas tan habitual en los anuncios de dicha casa. El entorno nos traslada hacia Andalucía, concretamente a Sevilla, pues tras el paso procesional, su fondo lo constituye la catedral de la ciudad y su claramente identificable Giralda. El mismo texto también rompe con la finalidad religiosa del evento al definir la Semana Santa como "La fiesta más simpática del año..."70.

Nuevas mantillas, en este caso de Federico Ribas, hacen acto de presencia en anuncios de la casa Gal ${ }^{71}$. Un grupo de tres jóvenes, debidamente ataviadas,

68 ABC, 1 de abril de 1923.

69 "San Jorge" (1450) y "San Jorge y el dragón" (1470) de Paolo Uccello, "San Jorge y el dragón" (1504) de Rafael. También será representada la escena por Durero, Donatello, Rubens y Gustave Moreau.

70 Nuevo Mundo, $n^{\circ} 1.578,18$ de abril de 1824, pág. 9. 

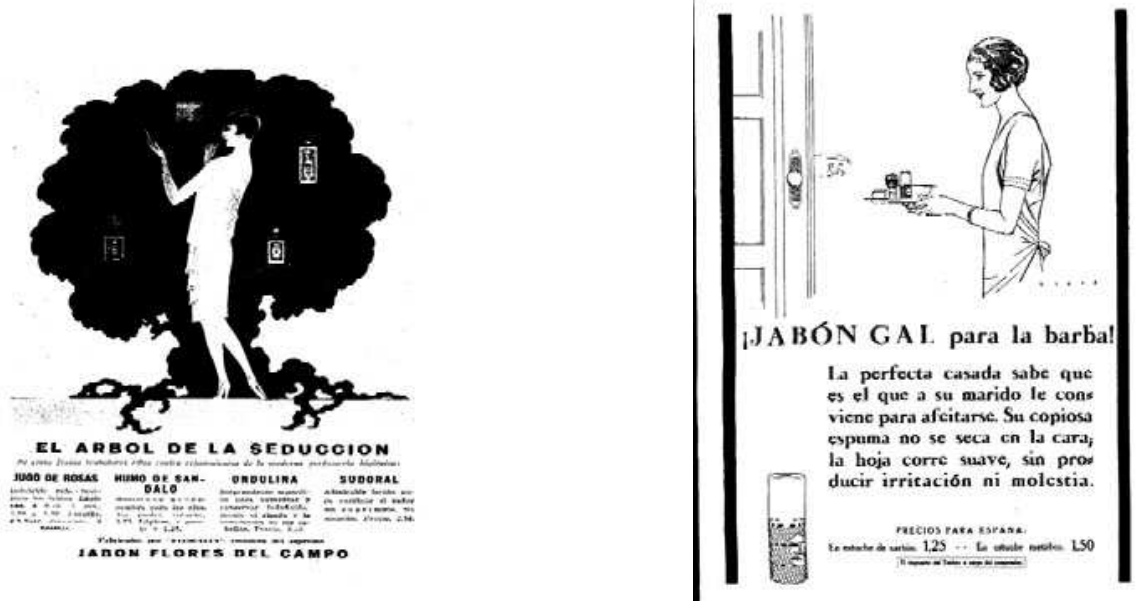

12. "Blanco y Negro", 13-11-1927.

13. Ilustración de Federico Ribas: "Blanco y Negro", 9-11-1927.

marchan de manera presurosa con sus devocionarios en mano. Desconocemos su destino pero bien pudieran dirigirse a participar de los oficios de Semana Santa o a integrarse a su hermandad correspondiente para iniciar la marcha de acompañamiento a su imagen devocional. Aunque más recreados en reflejar la belleza de las jóvenes que en el hecho religioso, no podemos eludir la carga de sacralidad que poseían estas iconografías, protagonistas habituales de los carteles que hacían anuncio de tan andaluza celebración.

\section{SACRALIZACIÓN DE LO PROFANO.}

En algunos anuncios no podríamos hablar de iconografías sagradas, dado que lo que nos presentan son imágenes contemporáneas pero, sin embargo, el texto nos da la pista para vincularlo con el ámbito de lo religioso. Uno de estos ejemplos estaría en el anuncio que la empresa Floralia utiliza para dar a conocer cuatro de sus creaciones consideradas como "... refinamientos de la moderna perfumería higiénica" 72. Se trata de los productos Jugo de Rosas, Humo de Sándalo, Ondulina y Sudoral, pintura de labios, sombra de ojos, rizador para el pelo y loción desodorante respectiva-

71 Idéntico anuncio podemos encontrarlo en Blanco y Negro, 20 de marzo de 1921 y en $A B C, 24$ de marzo de 1921.

72 Blanco y Negro, 13-11-1927. 
mente. Estos productos se designan como frutos tentadores que brotan del árbol de la seducción, clara alusión al árbol del bien y el mal antes referido del jardín del Edén. La imagen, por su parte, nos presenta la oscura silueta del citado árbol de la que penden las cuatro creaciones mientras que una joven resaltada en blanco se dispone ante él utilizando el primero de los citados objetos de la tentación [12].

No obstante, la tentación y la seducción pueden interpretarse como un mensaje para las jóvenes que adquieran los mencionados productos, las cuales lograrán tentar y seducir a los caballeros, embaucarlos del mismo modo que su antepasada lo consiguió con Adán.

También podemos incluir como sutilmente relacionado con la religión el anuncio que, de las manos de Federico Ribas, se encarga de publicitar la espuma de afeitar de la empresa Gal. La imagen no puede ser más profana pues nos presenta a una joven ama de casa ${ }^{73}$ que porta sobre una bandeja -elemento que centraliza la escena por ser el principal objeto de atención para el cliente- la espuma de afeitar, brocha, palangana y demás accesorios necesarios para el perfecto rasurado del esposo. El marido queda sugerido a través de una mano que asoma tras una puerta abierta -probablemente el cuarto de baño del domicilio- para recibir los productos que tan sabiamente su esposa ha adquirido.

Hasta aquí nada nos indicaría la inclusión de este anuncio en el estudio que nos ocupa pero, curiosamente, el texto del mismo nos indica que la mujer representada es "La perfecta casada...."74, denominación que nos remite título homónimo de la obra del poeta toledano Fray Luís de León publicará en Salamanca en 1583. En este caso una de sus escasas creaciones en prosa que dedicó a María Varela Osorio con motivo de su boda para que le sirviera de guía en su matrimonio. El comportamiento que toda mujer honesta debía seguir en su vida doméstica, según la recomendación de este libro, es por tanto el mismo que debe perseguir la esposa ideal de esas primeras décadas del siglo XX [13].

De nuevo Federico Ribas y también para un producto de la casa Gal, su famoso jabón Heno de Pravia, hallamos una representación similar a la citada anteriormente. No es una iconografía religiosa pero el texto nos remite a la fe, algo que si podemos relacionar con el mundo de lo sagrado. En esta ocasión se nos presenta un busto femenino enmarcado en un octógono y con los ojos vendados, mientras el texto no indica que las personas que usan este producto tienen "una fe ciega..."75 en su eficacia. Aunque realmente el hablar de fe, en el caso de un objeto cuyos beneficios se pueden apreciar por medio de los sentidos, sería un uso erróneo del término.

Otra situación similar, también de Federico Ribas, creada, al igual que la anterior, en el seno de Veritas -agencia que creo la propia empresa Gal para que se

\footnotetext{
73 Esta designación queda claramente expuesta al plasmarnos a una joven con delantal lo que la encuadraría dentro de una dedicación doméstica de cuidado del hogar y de sus habitantes.

74 Blanco y Negro, 9-11-1927.

75 Blanco y Negro, 8-12-1929. Ilustración Federico Ribas.
} 

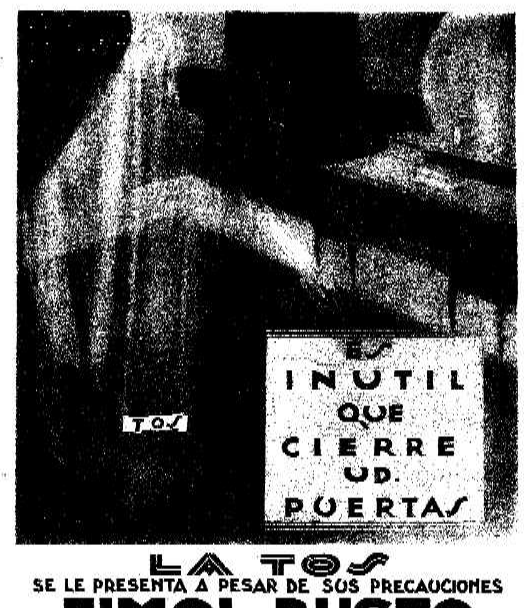

encargara de la publicidad de sus productos- nos presenta la imagen de unas manos vistas por el dorso y posándose una sobre la otra. De nuevo es el texto el que nos remite a lo religioso al describirnos las mismas como "Manos de Santa" y además como "espirituales"76.

En otros casos la religiosidad queda plasmada a través de figuras infantiles que, previamente a su reposo nocturno, se concentran en realizar sus oraciones, lo que queda de nuevo reseñado tanto por el texto, en algunas ocasiones, como por medio de la disposición arrodillada y con las palmas unidas de los niños. Son por tanto escenas que reflejan una sociedad católica y practicante en aquellas décadas y que inserta la oración como algo habitual en su vida cotidiana77.

Resulta curioso como para aludir a una enfermedad como es la tos, en lugar de hacer uso de las imágenes de esqueletos que había sido lo habitual por parte de los productos curativos cuando se quería hacer referencia a elementos que quebrantaran nuestra salud, se recurre a una imagen alegórica sumamente esperpéntica que más nos recordaría a la representación de un ser fantasmal y espectral. La tos, que penetra en un espacio íntimo como parece quedar aludido por la presencia del tocador, se encarna por medio de un busto de ojos muy abiertos, cabello cano y boca apenas sugerida, mientras el cuerpo queda totalmente difuminado. Apenas se aprecian unos pliegues que sugieren una especie de túnica, sin visualización de cuerpo interno, y a la derecha una mano que se está casi evaporando. El resultado es la sensación de encontrarnos con un ser de ultratumba o una especie de aparición cuando en

76 Blanco y Negro, 20-7-1930. Ilustración Federico Ribas.

77 Blanco y Negro, 4-11-1923 y 2-12-1923. 
realidad es una enfermedad lo que por este medio se está queriendo plasmar. El objeto publicitado es el Fimol Busto, jarabe contra los catarros, que combatirá a este ser espectral que queda identificado a través de una cartela. [14] La ilustración carece de firma por lo que no podemos identificar a quién se debe esta creación ${ }^{78}$.

Con todo lo dicho podemos advertir como unas iconografías que poco objeto tienen dentro del mundo publicitario, también hacen acto de presencia posiblemente debido a que la incesante creación de imágenes en este medio hizo necesario una continua inventiva y la recuperación de elementos del pasado como un medio de enganche con el espectador gracias a lo familiar de las mismas. Su presencia, en comparación con otro tipo de imágenes, fue escasa pero, como se ha podido observar, no inexistente y por tanto, resulta de interés observar esos usos que lo sagrado recibió en este nuevo entorno de la persuasión.

$78 A B C, 1$ de junio de 1924 . 